\title{
A SURVEY OF TELEPRACTICE IN SPEECH-LANGUAGE PATHOLOGY AND AUDIOLOGY IN INDIA
}

\author{
HARITHA S. MOHAN, M.SC SPEECH LANGUAGE PATHOLOGY ${ }^{1}$, AYESHA ANJUM, \\ M.SC SPEECH LANGUAGE PATHOLOGY ${ }^{1}$, PREMA K.S. RAO, PHD ${ }^{1}$ \\ ${ }^{1}$ INDIA INSTITUTE OF SPEECH AND HEARING, MYSURU, KARNATAKA, INDIA
}

\begin{abstract}
Telepractice has emerged as a form of service delivery to assess and treat individuals with communication disorders. The present study surveyed speech-language pathologists and audiologists in India about the use of telepractice. Two hundred and five $(\mathrm{N}=205)$ speech-language pathologists and audiologists responded to a questionnaire, with $12.19 \%$ reporting their use of telepractice to deliver clinical services. Respondents also indicated an urgent shortage of professionals in India to deliver clinical services in speech-language pathology and audiology, and opined that these needs can be met via the use of telepractice. India is well known throughout the world for the advanced application of Information and Communication Technology (ICT), with 931.95 million telephone subscribers, over 900 million mobile phone users, and the second-largest mobile phone usage in the world. India has also experienced a tremendous rise in the number of internet users. Therefore, India is well poised to fully develop telepractice to overcome the barriers of distance and amplify the availability of speechlanguage pathology, audiology and other healthcare services. But first, the widespread use of telepractice throughout the nation will require an improved infrastructure (e.g., to uphold privacy and security); training for professionals; and telepractice policies. While very promising, the deployment of telepractice throughout India will require the attention of policy makers and government organizations.
\end{abstract}

Keywords: Audiology, India, Speech Language Pathology, Telehealth, Telepractice

Innovation has led to technological advancements and the development of various forms of telecommunication systems. As a result of technological evolution, a large number of healthcare providers are employing telehealth. The term 'telemedicine' is used to describe the diagnostic and treatment services delivered over a distance by a physician, nurse, or related professional (Fong, Fong \& Li, 2011).

Similarly, speech-language pathologists and audiologists are engaging in telepractice through use of online videoconferencing systems and other dedicated telecommunication systems to provide diagnostic and intervention services over geographical distances to a range of patients with communication disorders. Telepractice has been defined as "the application of telecommunications technology to deliver professional services at a distance by linking clinician to client, or clinician to clinician for assessment, intervention, and/or consultation" (ASHA, 2005a). Telepractice offers significant benefits, as it provides greater access to speech-language pathology and audiology services; improves access of services to clients with linguistic and cultural diversity; increases ease of collaboration among multi-disciplinary team members; and saves travel time with cost benefits for clients.

There is now considerable evidence to support the premise that service delivery through telepractice may actually enhance the quality of care provided, and, ultimately, quality of life (McCue, Fairman, \& Pramuka, 2010; Winters \& Winters, 2004). Winters and Winters (2004) suggest that telepractice has the potential to optimize the timing, intensity, and sequencing of intervention, leading to the greatest functional outcome for the client. Twenty-five percent of studies that assessed clients' reactions to the use of telepractice reported favourable responses (Theodoros, 2011). It is also crucial to examine professionals' attitudes toward the use of telepractice. The American SpeechLanguage-Hearing Association (ASHA, 2002) conducted a survey on use of telepractice among audiologists and speech-language pathologists. ASHA reported that $11 \%$ of respondents delivered services using telepractice, and $43 \%$ expressed interest in using it in the future.

India has a population of 1.34 billion (http://www.mospi.gov.in), with $1.8 \%$ of total population estimated to have a disability (Rehabilitation Council of India, 2016). In contrast, the Indian Speech and Hearing Association (ISHA) (2015) estimates there are 2500 qualified speech-language pathologists and audiologists in India. These data indicate a very low ratio of potential service receivers to available service providers. Strategies are needed to meet the service demands of persons in India with communication disorders. 
On the positive side, India is well known throughout the world for the advanced application of Information and Communication Technology (ICT). India has 931.95 million telephone subscribers, over 900 million mobile phone users, and the second-largest mobile phone usage in the world. There has also been a tremendous rise in the number of internet users in India. At this juncture, telepractice use in India could overcome the barriers posed by distance and amplify the availability of speech and language services throughout the nation.

Additional research is required to determine if telepractice can be a viable form of service delivery in India. In contrast to Western countries, there is dearth of research evidence concerning telepractice in India. There is no reported data to account for the number of clinicians providing telepractice, the type of consultation services delivered, resource materials available, legal policies and guidelines for clients and clinicians, or training for telepractice service delivery. Hence there is a pressing need to examine the scope of telepractice in the India and the perspectives of clinicians.

The present study aims to explore telepractice in India. Speech-language pathologists and audiologists across the country were asked to complete an internet-based survey. Specifically, the study objectives were: (a) to report the status of telepractice in speech-language pathology and audiology in India; and (b) to report and compare the opinions of speech-language pathologists and audiologists about telepractice in India.

\section{METHOD}

\section{PHASE I: DEVELOPMENT OF QUESTIONNAIRE}

A questionnaire was developed to gather responses from two groups. Group I consisted of speech-language pathologists and audiologists engaged in telepractice. Group II included speech-language pathologists and audiologists not engaged in telepractice. The questionnaire was divided into two sections. The first section contained questions to collect demographic details of the participants in Groups I and II. The second section contained questions to elicit information from Group I about service delivery through telepractice. Twenty closed ended questions were included to study the perspectives of speech-language pathologists and audiologists on telepractice. Questions addressed four content areas: perceptions of professionals about service delivery through telepractice; characteristics of telepractice service; training and research in telepractice; and policies and guidelines for telepractice.
The questionnaire also included a sub-section with four questions for Group II on awareness of telepractice in speech-language pathology and audiology. Four additional mandatory questions were also included to elicit responses from Group I and Group II regarding the availability of telepractice providers in their regions; accessibility of resources for telepractice; and legal guidelines and policies in telepractice. The questionnaire was validated by five telepractitioners in speech-language pathology and audiology.

\section{PHASE II: ADMINISTRATION OF THE QUESTIONNAIRE}

The sampling frame for the survey was approximately 2800 speech-language pathologists and audiologists registered with the Indian Speech and Hearing Association (ISHA). The questionnaire was configured with features of Google form and e-mailed to the registered ISHA members. All India Institute of Speech and Hearing Ethical Guidelines for Bio-Behavioural Research 2.1e and 2.4c were followed for the current study (Basavaraj, 2009). The e-mail included a letter of consent, objectives of the research, and the link to the survey questionnaire. Each participant was required to read an informed consent letter in which they agreed to the terms and conditions of the survey. Responses were collected over a period of three months, and kept confidential.

\section{PHASE III: ANALYSES OF RESPONSES}

Participant responses were analysed by computing percentage values for the 20 questions. This was carried out separately for the overall responses of all participants (Groups I and II); for professionals engaged in telepractice (Group I); and professionals engaged in in-person service delivery (Group II). Further, a non-parametric statistical test (Test for equality of proportions) was employed for five questions (Q14, Q15, Q16, Q19, \& Q20) to compare the opinions of professionals engaged in conventional in-person service delivery and service delivery through telepractice.

\section{RESULTS}

\section{DEMOGRAPHICS}

A total of 205 speech-language pathologists and audiologists completed the survey, a response rate of $7 \%$. Responses were received from different states across India. 
Among the professionals, $48 \%(\mathrm{~N}=83))$ were speechlanguage pathologists; $18.04 \%(\mathrm{~N}=37)$ were audiologists and $41.46 \%(\mathrm{~N}=85)$ were speech-language pathologists and audiologists. All were engaged in providing clinical services. Group II included $87.80 \%(\mathrm{~N}=180)$ of the respondents who reported providing in-person service delivery. Approximately $12.19 \%(\mathrm{~N}=25)$ of the respondents reported using telepractice to deliver clinical services and were included in Group I.

Among the professionals engaged in telepractice (Group I), speech-language pathologists were more likely to deliver speech and language therapy services than audiologists. Figure 1 depicts the percentage of professionals engaged in delivery of services through telepractice. Furthermore, $40 \%(\mathrm{~N}=10)$ provided both speech-language pathology and audiology services through telepractice.

Professionals delivering services through telepractice

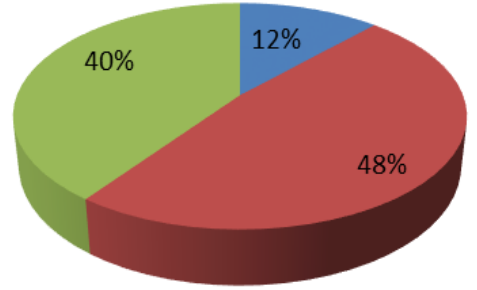
audiologists
- Speech language pathologists
Audiologists and speech language pathologists

Figure 1. Professionals delivering services through telepractice $(\mathrm{N}=205)$.

\section{SURVEY FINDINGS}

\section{PERCEPTIONS OF PROFESSIONALS ENGAGED IN IN-PERSON SERVICE DELIVERY}

The perceptions of speech-language pathologists and audiologists engaged in in-person service delivery (Group II) were examined in the following areas.

- Awareness of telepractice

- Viability of service delivery

- Requirement of certification for telepractice

- Infrastructure required

It was found that $55 \%(\mathrm{~N}=172)$ of the professionals were aware of service delivery through telepractice. Ninety percent $(\mathrm{N}=162)$ of the respondents perceived that telepractice can be a viable form of service delivery; $73.3 \%$
( $N=132$ ) opined that the professional must be certified for telepractice; and $81.66 \%(\mathrm{~N}=147)$ stated that the infrastructure required for service delivery through telepractice is different from conventional in-person service delivery.

To an overwhelming degree, $92 \%(N=166)$ of participants were of the opinion that there is inadequate number of telepractice providers in their respective states in India. In addition, the survey revealed that $83.90 \%(\mathrm{~N}=151)$ of the professionals believed that sufficient resources are not available for telepractice. Most, $92.68 \%(\mathrm{~N}=167)$ were of the opinion that legal guidelines are needed for telepractice in India.

\section{VIEWS OF TELEPRACTITIONERS IN SPEECH-LANGUAGE PATHOLOGY AND AUDIOLOGY}

Only $12.19 \%(\mathrm{~N}=15)$ of the respondents reported using telepractice to deliver clinical services (Group I). Among the professionals engaged in telepractice, $48 \%(\mathrm{~N}=12)$ are speech-language pathologists and $12 \%(\mathrm{~N}=3)$ are audiologists. Within this group, $56 \%(\mathrm{~N}=14)$ of the professionals reported that they provide teletherapy services within India and 44\% ( $N=11)$ provide services in other countries.

To compare opinions of Group I and Group II for the question regarding availability of telepractice providers in their respective states across India, the test for equality of proportions was carried out, using Smith's Statistical Package, version 1.0. This statistical test determines the difference between the population proportions. The test results suggest no significant difference between the opinions of Group I and II concerning the unavailability of telepractice service providers in their respective states in India (0.120, p> .05, $|z| 1.55)$.

\section{CHARACTERISTICS OF TELEPRACTITIONERS}

\section{SETTINGS OF SERVICE DELIVERY THROUGH TELEPRACTICE}

Figure 2 represents percentages of the most common settings where clinicians provided tele-speech and teleaudiology services.

Results revealed that $36 \%(\mathrm{~N}=9)$ of telepractice providers were self-employed; $24 \%(\mathrm{~N}=6)$ were an employee of a public or a private non-profit organization; $20 \%(\mathrm{~N}=5)$ were an employee of a central government organization; and $4 \%(\mathrm{~N}=1)$ were an employee of a private organization. 


\section{Setting of service delivery through telepractice}

Client's home

Elementary school

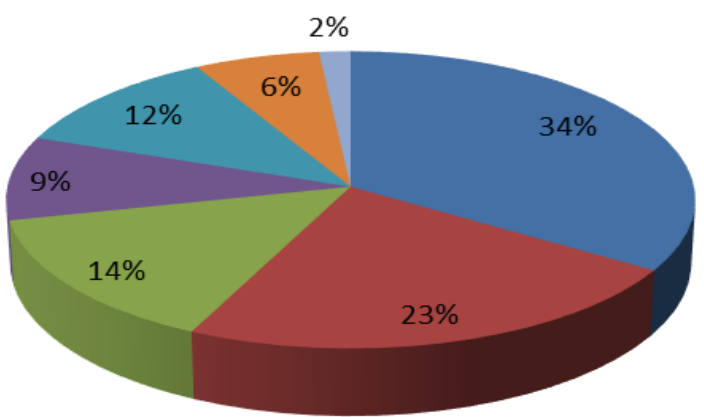

- Pre-elementary school

Speech and hearing centre and secondary school

- Special day/Residential school and clinic chain or franchise

- College/ University and Audiologists and Speech language pathologist clinic

- General medical and rehabilitation hospital

Figure 2. Settings of service delivery through telepractice.

\section{AGE GROUPS SERVED THROUGH TELEPRACTICE}

Telepractice services were provided to clients throughout the lifespan. Table 1 shows the percentage of telepractitioners providing clinical services across various age groups.

Table 1. Age Range Served By Telepractice Service Providers

\begin{tabular}{ll}
\hline Age range & $\%$ of Respondents \\
\hline Infants & $12.97 \%$ \\
Paediatric & $33.76 \%$ \\
Adolescents & $14.28 \%$ \\
Adults & $20.82 \%$ \\
Older adults & $18.17 \%$ \\
\hline
\end{tabular}

\section{TYPES OF SERVICE DELIVERY}

As shown in Table 2, telepractice service providers variously delivered screening, assessment, management, follow-up or monitoring/ guidance and/or professional consultation.

Table 2. Services Delivered Through Telepractice

\begin{tabular}{ll} 
Age range & $\%$ of respondents \\
Screening & $15.27 \%$ \\
Assessment & $19.44 \%$ \\
\hline Management & $20.83 \%$ \\
\hline Follow-up/monitoring guidance & $27.77 \%$ \\
\hline & \\
\hline
\end{tabular}




\section{DISORDERS SERVED THROUGH TELEPRACTICE}

Table 3 presents a summary of the disorder areas for which telepractice services were provided.

Table 3. Disorders Served Through Telepractice

\begin{tabular}{|c|c|}
\hline Areas & $\%$ of respondents \\
\hline $\begin{array}{l}\text { Speech sound disorders in } \\
\text { children }\end{array}$ & $12.09 \%$ \\
\hline Learning disability & $9.67 \%$ \\
\hline $\begin{array}{l}\text { Childhood receptive and } \\
\text { expressive language disorders }\end{array}$ & $8.87 \%$ \\
\hline $\begin{array}{l}\text { Cognitive communication } \\
\text { disorders }\end{array}$ & $6.45 \%$ \\
\hline Fluency disorders in adults & $7.25 \%$ \\
\hline Adult language disorders & $5.64 \%$ \\
\hline $\begin{array}{l}\text { Voice and resonance disorders } \\
\text { in adults }\end{array}$ & $5.64 \%$ \\
\hline $\begin{array}{l}\text { Speech sound disorders in } \\
\text { adults }\end{array}$ & $5.64 \%$ \\
\hline Autism spectrum disorders & $4.83 \%$ \\
\hline Accent modification & $4.83 \%$ \\
\hline $\begin{array}{l}\text { Voice and resonance disorders } \\
\text { in children }\end{array}$ & $4.83 \%$ \\
\hline Fluency disorders in children & $4.83 \%$ \\
\hline Aural rehabilitation & $4.03 \%$ \\
\hline $\begin{array}{l}\text { Hearing aid or assistive } \\
\text { technology maintenance }\end{array}$ & $4.03 \%$ \\
\hline Auditory verbal therapy & $3.22 \%$ \\
\hline Motor speech disorders & $1.61 \%$ \\
\hline Tinnitus & $1.61 \%$ \\
\hline Auditory processing disorders & 0.80 \\
\hline $\begin{array}{l}\text { Motor speech disorders in } \\
\text { children }\end{array}$ & $0.80 \%$ \\
\hline
\end{tabular}

Results revealed that some disorders such as childhood aphasia, specific language impairment, motor speech disorders in children, dysphagia in children and adults, auditory processing disorders and vestibular disorders were managed via telepractice.

Fifty-six percent of the telepractitioners $(\mathrm{N}=14)$ reported they had received positive feedback from clients about telepractice services. In addition, $64 \%(\mathrm{~N}=16)$ of telepractitioners reported client satisfaction with follow-up/ monitoring, and better access to services. Sixty percent $(\mathrm{N}=$ 15) reported client satisfaction concerning the regularity of telepractice services.

\section{TRAINING AND RESEARCH IN TELEPRACTICE}

One hundred percent of respondents in Group I ( $\mathrm{N}=12)$ and $28 \%(\mathrm{~N}=50)$ in Group II were of the opinion that a postgraduate degree in speech-language pathology or audiology is required to be qualified to deliver telepractice. In contrast, 28\% ( $\mathrm{N}=7)$ of respondents in Group I and 9.4\% $(\mathrm{N}=17)$ in Group II suggested that a short-term training certification course in telepractice should be made mandatory for professionals to deliver clinical services through telepractice.

Ninety-two percent $(\mathrm{N}=23)$ of respondents in Group I and $97.22 \%(\mathrm{~N}=175)$ in Group II, have not authored a publication on telepractice. This suggests a dearth of research on telepractice in speech-language pathology and audiology in India. Furthermore, $68 \%(\mathrm{~N}=17)$ of respondents in Group I and $86.11 \%(\mathrm{~N}=155)$ in Group II reported that there are currently insufficient resources (i.e., structural framework; technical support, materials) to provide appropriate speech-language pathology and audiology services in India.

\section{POLICIES AND GUIDELINES FOR TELEPRACTICE}

A large number of respondents, $92 \%(\mathrm{~N}=23)$ in Group I and $92.77 \%(\mathrm{~N}=167)$ in Group II) were of the opinion that there should be mandatory legal guidelines for the conduct of telepractice in speech-language pathology and audiology. Eighty-eight percent ( $\mathrm{N}=22)$ of respondents in Group I and $58.04 \%(\mathrm{~N}=119)$ in Group II opined that policies and technologies should protect clinician and client privacy and security in telepractice.

Finally, $72 \%(\mathrm{~N}=18)$ of the respondents in Group I stated that a standard protocol to document the services delivered via telepractice is essential. 


\section{DISCUSSION}

This article surveyed the opinions of speech-language pathologists and audiologists about telepractice in the Indian sub-continent. Results suggest that $95.55 \%(\mathrm{~N}=172)$ of speech-language pathologists and audiologists who provide in-person service delivery (Group II) were aware that telepractice can be a form of service delivery. However, only $12.19 \%(\mathrm{~N}=25)$ of the survey respondents are engaged in telepractice (Group I) in India. This is similar to the findings of a 2002 survey of speech-language pathologists in the United States (ASHA, 2002). In the current study, among the professionals engaged in telepractice (Group I), speechlanguage pathologists were more likely than audiologists to engage in tele-speech therapy. Most of the professionals surveyed agreed that telepractice can be a viable form of service delivery to assess and treat persons with communication disorders.

Clients in India have limited access to speech-language and audiology services, as there is a shortage of service providers (Rao \& Yashaswini, 2017). Respondents in the current survey expressed that there is an urgent need to meet the demands of the individuals seeking services in their respective states across India. This could be made possible if professionals could engage in telepractice to offer clinical services in speech-language pathology and audiology.

Furthermore, professionals were of the opinion that the infrastructure required for telepractice is significantly different from conventional service delivery. Newer technology enables clinicians to use laptops and tablets along with low-cost web-based videoconferencing systems. Technology has greatly enhanced the audio and video hardware and software that enables clinicians to offer quality services to their clients in a cost-effectiveness manner. When an adequate technological infrastructure is provided (e.g., to improve the likelihood of a trouble-free videoconferencing session) telepractice can be affordable, flexible, and reliable. For India, this points to a pressing need to lay norms for technical infrastructure for telepractice service delivery.

Based on the results of this survey, service providers in India have primarily learned to implement telepractice through personal experience rather than formal training. Most professionals engaged in telepractice in India were of the opinion that formal training and certification are necessary for professionals who employ this service delivery model. Systematic and comprehensive training in telepractice will be crucial as the use of telepractice increases in the future.

The privacy and security of both clients and clinicians are of critical importance in telepractice. Survey respondents recognized that use of open, unencrypted platforms poses inherent risks to privacy and security. The software in public domains that are largely in current use by telepractitioners in India poses a serious threat to the privacy security of both clinicians and clients. There is an urgent need to employ secured, licensed services while engaging in service delivery through telepractice. There is also a compelling need to put forth legal guidelines and policies for safe and secure service delivery.

There is the need to examine an even greater number of factors critical to telepractice service delivery in India. The current survey is limited in scope. First, the number of respondents is relatively small, although it is the representative of the relatively few professionals engaged in telepractice in India. Second, the survey did not collect any information on the infrastructure available to telepractitioners, the resource materials used, or the challenges faced by the telepractitioners during their sessions.

In spite of these limitations, this survey suggests an opportunity to examine, reform, and even create new guidelines for telepractice in India. And most significantly, it points to the pressing need for technological support and training to enable professionals to offer quality services. The insight gained from this survey offers directions to improve service delivery through telepractice in a country that already is well known throughout the world for the advanced application of Information and Communication Technology (ICT).

The findings of the survey endorse the feasibility of providing speech-language and audiology services through telepractice. The results reflect the opinion of the professionals for whom telepractice is a plausible mode of service delivery. The extensive technology available to healthcare providers such as speech-language pathologists and audiologists, and their clients, should be used to its fullest extent to enable better quality care in settings and regions where the physical presence of expertise is unavailable.

\section{REFERENCES}

29th Annual report 2015-16 of the Department of Empowerment of Persons with Disabilities, Rehabilitation Council of India, 2016 Retrieved from http://www.rehabcouncil.nic.in/ writereaddata/29thEnglishAR.pdf

American Speech-Language-Hearing Association (2005a). Knowledge and skills needed by speech-language pathologists providing clinical services via telepractice [Knowledge and Skills]. Retrieved from https://doi: 10.1044/policy.KS2005-00077

American Speech-Language-Hearing Association. (2011). Survey of telepractice use among audiologists and speech-language pathologists, 2002. 
Basavaraj, V. (2009). Ethical guidelines for bio-behavioural research. Mysore: All India Institute of Speech and Hearing.

Fong, B., Fong, A. C. M., \& Li, C. K. (2011). Telemedicine technologies: Information technologies in medicine and telehealth. West Sussex, United Kingdom: John Wiley \& Sons.

Indian Speech and Hearing Association (2015). Retrieved on August 15, 2017, from http://www.ishaindia.org.in/

Indian Speech and Hearing Association. Members on roll as of 12 May, 2017. Retrieved from http://www. ishaindia.org.in/

McCue, M., Fairman, A., \& Pramuka M. (2010). Enhancing quality of life through telerehabilitation. Physical Medicine and Rehabilitation Clinics of North America, 21, 195-205. https://doi: 10.1016/j.pmr.2009.07.005
NSSO (2002) GOI. Ministry of statistics and programme implementation, National Sample Survey Office. (2002) Retrieved from http://www.mospi.gov.in

Rao, K.S., \& Yashaswini, R. (2017). Tele service in speechlanguage pathology and audiology prospects and challenges. Manuscript submitted for publication.

Theodoros, D. (2011). Telepractice in speech-language pathology: The evidence, the challenges, and the future. Perspectives on Telepractice, 1(1), 10-21. https:// doi:10.1044/tele1.1.10

Winters, J. M., \& Winters, J. M. (2004). A telehomecare model for optimizing rehabilitation outcomes. Telemedicine Journal \& EHealth, 10, 200-212. https://doi.org/10.1089/tmi.2004.10.200 


\section{APPENDIX}

A Survey of Telepractice in Speech-Language Pathology and Audiology in India

The objectives of the survey are,

i. To study existing service delivery through telepractice in India

ii. To understand professionals' views of on telepractice in speech-language pathology and audiology

*Indicates mandatory questions which cannot be skipped by the participants

\section{Informed consent ${ }^{\star}$}

I have been informed by the investigators about the study entitled "A survey of telepractice in Speech-Language pathology and audiology in India" I understand the purpose and procedures of the study. I declare that my participation in this study is entirely voluntary and that I may withdraw at any time without incurring a penalty. I do not have any financial or non-financial benefits from this study. I hereby give my consent to participate.

I Agree

I Disagree

Name*:

Age/Sex*:

Professional qualification*:

Date*:

\section{Instructions}

Please answer the following questions pertaining to telepractice in speech-language pathology and audiology

1. In which state do you currently reside?*

2. Do you currently provide clinical services?*

Yes

No

3. In which specialty do you provide clinical services?

Speech-Language Pathology

Audiology

Both

4. Do you provide clinical services in speech-Language pathology and/ or audiology through telepractice?* Yes

No

If no,

Are you aware of telepractice in speech-language pathology and/or audiology?

Yes

No

Do you feel telepractice can be a viable form of service delivery?

Yes

No 
Do you think one has to be certified for telepractice?

Yes

No

Do you feel infrastructure required for telepractice is same as face-to-face service delivery?

Yes

No

If yes, respond to the questions below

5. To which state and/ or country do you currently deliver telepractice services?

6. Which of the following best describes your employer?

Self-employed (e.g., run own practice)

Employee of a central or a state government organization

Employee of a public or a private non-profit organization

Others

7. In what type(s) of facilities are the clients you serve through telepractice? (select all that apply.)

Pre-elementary (preschool)

Elementary school

Secondary school

Special day/ residential school

Clients home

College or university

General medical hospital

Rehabilitation hospital

Private physician's office

Audiologist or Speech-Language pathologist's clinic

Speech and hearing center

Clinic chain or franchise

Others

8. What age groups do you regularly serve through telepractice? (select all that apply.)

$<6$ months

7 months - 2 years

3 - 5 years

6 - 11 years

12 - 17 years

18 - 64 years

65 - 74 years

$>75$ years 
9. What type of services do you deliver through telepractice? (select all that apply.)

Screening

Assessment

Management

Follow-up/ monitoring/ guidance

Professional consultation

Others

10. In what area(s) do you provide services through telepractice? (select all that apply.)

Accent modification (e.g., speech intelligibility in multi-linguals, second language learning, etc.,)

Childhood receptive and expressive language disorder

Childhood aphasia

Learning disability

Autism spectrum disorders

Specific language impairment

Voice and resonance disorders in children

Speech sound disorder in children

Fluency disorders in children

Motor speech disorders in children (e.g., dysarthria, apraxia, etc.,)

Dysphagia in children

Adult language disorders (e.g., aphasia, dementia, etc.,)

Cognitive communication disorders

Voice and resonance disorders in adults

Speech sound disorders in adults

Fluency disorders in adults

Motor speech disorders (e.g., dysarthria, apraxia, etc.,)

Dysphagia in adults

Auditory verbal therapy

Aural rehabilitation

Auditory processing disorders

Hearing aid or assistive technology maintenance

Vestibular disorders

Tinnitus

Others

11. Do you, or does your employer, receive payment for services delivered through telepractice?

Yes

No

Uncertain 
12. Which of the following qualification(s) do you feel is the most appropriate for telepractice? (select all that apply.)

B.Sc. Speech-Language Pathology and Audiology

M.Sc. Speech-Language Pathology/ Audiology

Diploma in Speech-Language and Hearing Sciences

Short term certification course in telepractice

13. What benefits have your clients realized from services through telepractice?

Regularity in service

Satisfactory follow-up or monitoring

Better access to service with respect to cost vs. benefit

14. In your opinion, are there adequate tele service providers in your state?*

Yes

No

15. Do you have any publications on telepractice in Speech-Language and/ or audiology?*

Yes

No

16. Do you feel that the resources available are appropriate and sufficient for telepractice?*

Yes

No

17. Do you follow a standard protocol for documentation of your tele sessions?

Yes

No

18. What is the feedback offered by your clients about tele services?

Very good

Good

Satisfactory

Not satisfactory

19. Are legal guidelines required for telepractice?*

Yes

No

20. Do you feel that policies and technologies protect clinician and client privacy and security?* Yes

No

Thank you for your participation! 
This work is licensed under a Creative Commons Attribution 4.0 International License.

This journal is published by the University Library System of the 